\title{
Ventricular late potentials and spontaneous ventricular arrhythmias after surgical repair of tetralogy of Fallot: do they have prognostic value?
}

\author{
Dider Giroud, Marc Zimmermann, Richard Adamec, Ingrid Oberhänsli, Beat Friedli
}

\begin{abstract}
Objective-To determine the prognostic significance of ventricular late potentials and spontaneous ventricular arrhythmias detected early after surgical repair of tetralogy of Fallot.

Design-Prospective observational.

Setting-Cardiology department of a teaching hospital.

Methods-Between June 1984 and June 1991, 104 children (63 boys, 41 girls) were studied by signal averaging and 24 hour ambulatory monitoring after surgical repair of tetralogy of Fallot. Mean (SD) age at operation was 6 (3) years, mean interval between operation and evaluation was 8 (25) months, and the follow up after evaluation was one to 88 (mean 30) months.

Results-Ventricular late potentials were detected in 24/104 patients (23\%) and spontaneous ventricular arrhythmias in $39 / 96$ patients (38\%); usually (in $81 \%$ ) these were unifocal and rare. Patients with ventricular late potentials were older at operation than patients without late potentials $(9$ (3) $v 6$ (3) years, $P=$ $0 \cdot 002)$. No correlation was found between the presence of ventricular late potentials and the presence or complexity of spontaneous ventricular arrhythmias early after operation. During the mean follow up of $2 \cdot 5$ years no case of sudden death or sustained ventricular tachycardia was found. Conclusion-Short-term prognosis after surgical repair of tetralogy of Fallot is good; ventricular late potentials and spontaneous ventricular arrhythmias are often detected shortly after operation, but in the medium term follow up they do not predict sudden death or serious ventricular arrhythmias.
\end{abstract}

(Br Heart F 1994;72:580-583)

Cardiology Centre

D Giroud

M Zimmermann

$R$ Adamec

Paediatric Cardiac

Unit, University

Hospital, Geneva,

Switzerland

I Oberhänsli

B Friedli

Correspondence to: Dr Marc Zimmermann, Cardiology Center, University Hospital, 24 rue Micheli-du-Crest, 1211 Geneva 4, Switzerland.

Accepted for publication 16 May 1994 inducible ventricular tachycardia during programmed ventricular stimulation. ${ }^{15}{ }^{17}$ The true prognostic value of these tests is unknown, and the only three recognised variables associ-
Sudden death and ventricular arrhythmias repair of tetralogy of Fallot 1-8 $^{-1}$ Several marker of an increased risk of arrhythmia have been extra systoles during Holter recording, ${ }^{910}$ ventricular extra systoles during exercise tests, ${ }^{11}$ presence of ventricular late potentials, ${ }^{12-16}$ or ated with a poor outcome are advanced age at operation, longer follow up after repair, ${ }^{17}$ and poor haemodynamic results. ${ }^{10} 17$ The purposes of this study were to assess, on a mid-term basis, the prognostic significance of ventricular late potentials and spontaneous ventricular arrhythmias after surgical repair of tetralogy of Fallot.

\section{Patients and methods \\ PATIENTS}

From June 1984 to June 1991, 104 patients (two series of unselected, consecutive patients) who underwent surgical correction of tetralogy of Fallot at the University Hospital of Geneva, Switzerland, were studied. The mean (SD) age at operation was 6 (3) (range 1 to 15 ) years; the relatively old age at the time of operation is related to the fact that most patients operated on at our hospital were referred from developing countries. There were 63 boys (61\%) and 41 girls $(39 \%)$. Mean age at the time of the study (Holter recording and signal averaging) was 7 (4) (range 1 to 15) years. Mean interval between operation and evaluation was eight (range 1 to 150 ) months. In $88 \%$ of the cases (91/104), evaluation was performed during the first three months after surgical repair, in most cases during postoperative cardiac catheterisation. In all cases, haemodynamic data were collected, together with signal averaged electrocardiographic and Holter data. All patients were in sinus rhythm at the time of the evaluation and all had postoperative right bundle branch block.

\section{SIGNAL AVERAGING}

Signal averaged recordings were performed with a very high gain averaging system developed at our institution and described previously. ${ }^{13}$ The signal was amplified $10^{5}$ to $10^{6}$ times; band pass filters were set at 100 and $300 \mathrm{~Hz}$ (12 dB/octave); the averaging process was performed on 40 consecutive cardiac cycles and body surface recordings were obtained from two bipolar chest leads (between V2 and V4; between V4 and V6) after careful preparation of the skin. For each electrode position, three or more consecutive signal averaged recordings were obtained to confirm the reproducibility of any abnormal signal detected. Quantitative assessment included measurement of total filtered QRS duration (in $\mathrm{ms}$ ), and measurement of the interval between the end of the QRS complex and the point (determined retrogradely) when 
Simple linear correlation between age at evaluation and $(A)$ duration of total filtered $Q R S$ complex, (B) duration of low amplitude signals in the terminal complex ( $I_{40}$ interval).

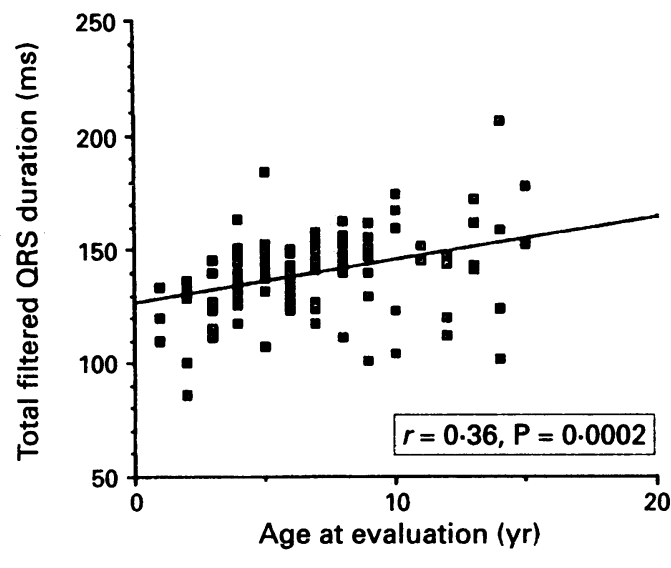

QRS voltage reached $40 \mu \mathrm{V}\left(\mathrm{I}_{40}\right.$, in $\left.\mathrm{ms}\right)$. With the equipment and the band pass filtering used in our laboratory, late potentials were considered to be present by visual identification or if the total QRS duration was $>140 \mathrm{~ms}$ and if the interval between the end of QRS and the $I_{40}$ was $>50 \mathrm{~ms}$ in the presence of right bundle branch block. ${ }^{15}$

TWENTY FOUR HOUR AMBULATORY ELECTROCARDIOGRAPHIC MONITORING (HOLTER RECORDING)

Twenty four hour ambulatory electrocardiographic monitoring was performed in all patients with a two channel tape recorder and was analysed by a dynamic electrocardioscanner (Del Mar Avionics, model 447). Ventricular arrhythmias were classified according to the Deanfield classification (= Lown modified). ${ }^{1} 1=$ unifocal, $<30 / \mathrm{h}$ (peak); $2=$ unifocal, $30 / \mathrm{h} ; 3=$ couplets, multifocal, $<30 / \mathrm{h} ; 4=$ couplets, multifocal, $>30 / \mathrm{h}$; 5 = non-sustained ventricular tachycardia. Arrhythmias of Deanfield class $\geq 2$ were regarded as important.

\section{FOLLOW UP}

Information was obtained by questionnaire directly from the attending physician or from the institution where regular follow ups were performed.

\section{STATISTICAL ANALYSIS}

All values are expressed as means (SD). Numerical data were compared with Student's $t$ test for unpaired data. Categorical data were compared with $\chi^{2}$ analysis. A simple linear regression analysis was used to establish a relation between age at evaluation and the quantitative variables of the signal averaged electrocardiogram. A value of $\mathrm{P}<0.05$ was considered to be significant.

\section{Results}

SIGNAL AVERAGING

Late potentials were detected from the body surface in $24 / 104$ children (23\%). Mean duration of $\mathrm{I}_{40}$ interval was 42 (15) ms and mean duration of total filtered QRS duration was 140 (19) ms. A positive linear correlation was found between age at evaluation and total filtered QRS duration $(r=0.36, P=0.0002)$

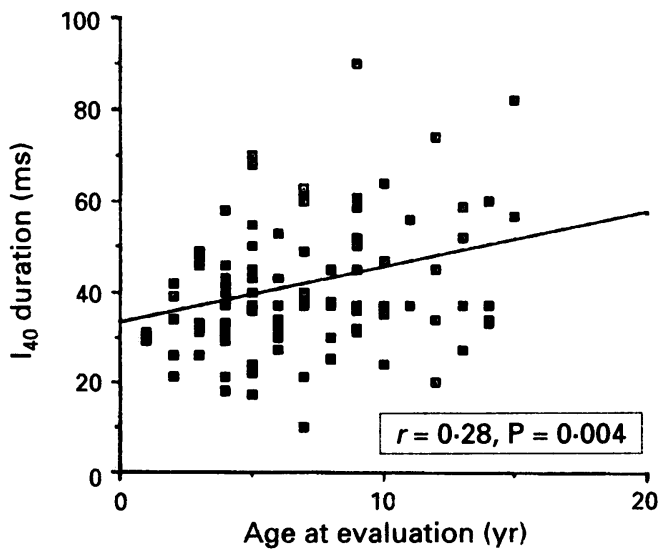

or $\mathrm{I}_{40}$ interval $(r=0 \cdot 28, \mathrm{P}=0.004$, figure).

HOLTER RECORDINGS

Ninety six children had a twenty four hour electrocardiographic monitoring at the time of signal averaging. Ventricular arrhythmias were found in 36 cases ( $38 \%$ ). Table 1 shows the distribution of ventricular arrhythmias according to the Deanfield classification. In most cases $(81 \%)$, ventricular arrhythmias were classified as $<2$ (NS).

Twenty two out of 24 children with late potentials had twenty four hour electrocardiographic monitoring. Table 2 shows that ventricular arrhythmias were detected in nine of 22 cases ( $41 \%$ ), but only two of nine children $(22 \%)$ had significant ventricular arrhythmias.

In the absence of late potentials, ventricular arrhythmias were detected in $36 \%$ of the cases (27/74); again, most recordings (81\%) showed non-significant ventricular arrhythmias. The three patients with non-sustained ventricular tachycardia during Holter recording belonged to this subset of patients without late potential. No correlation was found between the presence of ventricular late potentials and the presence or severity of spontaneous ventricular arrhythmias during Holter recording.

Table 1 Incidence and severity of spontaneous ventricular arrhythmias as detected by Holter recording

\begin{tabular}{lc}
\hline & No (\%) \\
\hline Ventricular arrhythmias present* & $36 / 96(38)$ \\
1 & $29 / 36(81)$ \\
2 & $0 / 36(0)$ \\
3 & $3 / 36(8)$ \\
4 & $1 / 36(3)$ \\
5 & $3 / 36(8)$ \\
\hline
\end{tabular}

^Deanfield classification.

Table 2 Incidence of spontaneous ventricular arrhythmias in the presence (or absence) of ventricular late potential (VLPS)

\begin{tabular}{llll}
\hline & $\begin{array}{l}\text { VLP present } \\
(n=22)\end{array}$ & $\begin{array}{l}\text { VLP absent } \\
(n=74)\end{array}$ & $P$ value \\
\hline Ventricular arrhythmias $^{\star}$ & $9 / 22(41 \%)$ & $27 / 74(36 \%)$ & $0 \cdot 70$ \\
1 & $7 / 9$ & $22 / 27$ & $0 \cdot 80$ \\
2 & $0 / 9$ & $0 / 27$ & 0.90 \\
3 & $2 / 9$ & $1 / 27$ & $0 \cdot 08$ \\
4 & $0 / 9$ & $1 / 27$ & $0 \cdot 55$ \\
5 & $0 / 9$ & $3 / 27$ & $0 \cdot 28$ \\
\hline
\end{tabular}

^Deanfield classification 
Table 3 Haemodynamic data (obtained during postoperative catheterisation) in patients with or without ventricular late potentials (VLPs)

\begin{tabular}{llll}
\hline & VLP present $(n=17)$ & VLP absent $(n=51)$ & $P$ value \\
\hline RV systolic pressure $(\mathrm{mm} \mathrm{Hg})$ & $41(12)$ & $45(15)$ & 0.39 \\
RV end diastolic pressure (mm Hg) & $6(2)$ & $6(2)$ & $0 \cdot 44$ \\
Pressure gradient RV/PA (mm Hg) & $18(12)$ & $20(16)$ & 0.55 \\
\hline
\end{tabular}

$\mathrm{RV}$, right ventricle; $\mathrm{PA}$, pulmonary artery.

\section{CIINICAL CHARACTERISTICS}

Compared with patients without ventricular late potentials, patients with ventricular late potentials were older at the time of the study (9 (3) $v 6$ (3) years, $\mathrm{P}=0.002$ ) and older at the time of operation ( 8 (4) $v 6$ (3) years, $\mathrm{P}=$ $0 \cdot 02)$. We found no correlation between ventricular late potentials and the following variables: (a) time interval between operation and evaluation; (b) duration of follow up after evaluation; (c) duration of follow up after surgery, (d) sex; (e) incidence of spontaneous ventricular arrhythmias; or $(f)$ postoperative haemodynamic variables (table 3 ).

Compared with patients without spontaneous ventricular arrhythmias, patients with ventricular arrhythmias during Holter recording were not older at the time of surgical repair. The only significant variable associated with the presence of spontaneous ventricular arrhythmias was the duration of follow up after operation $(P=0.04)$.

\section{FOLLOW UP}

The mean follow up after evaluation by signal averaging and Holter monitoring was 30 (range one to 88) months. A follow up >3 months was obtained in $79 \%$ of the cases. The mean follow up after the surgical repair was 38 (range 2 to 205) months. During the follow up period, there were no sudden deaths, no unexpected deaths, and no documented spontaneous sustained ventricular arrhythmia. No patient received antiarrhythmic drug treatment. Two patients died ( $2 \%$ ), one from heart failure after reoperation and one from a cerebrovascular accident.

\section{Discussion}

Sudden death after surgical repair of tetralogy of Fallot is a known complication, but is fortunately infrequent, with an incidence of $1-3 \% .^{2-6}$ Whereas some centres have found sudden death to occur most often in the first two years after the operation, ${ }^{7}$ others have shown an increased hazard with time after operation, with a maximum after 10 years. ${ }^{18}$ Sudden death seems to be related more to severe ventricular arrhythmias than to conduction disturbances, ${ }^{38}$ but prognosis seems favourable in most cases even when spontaneous ventricular arrhythmias are present. ${ }^{1920}$ In our study as in others ${ }^{1921}$ no case of sudden death and no case of sustained ventricular arrhythmia were found during follow up.

After surgical repair of tetralogy of Fallot, the incidence of spontaneous ventricular arrhythmias seems to be high (38\% in our study), but in most cases these arrhythmias are unimportant, only three patients $(8 \%)$ had runs of non-sustained ventricular tachycardia during 24 hour Holter monitoring. In our study the incidence of severe ventricular arrhythmias (Deanfield class $\geq 2$ ) was lower than previously described by others, ${ }^{9}{ }^{1922-23}$ but the study population and duration of follow up were not strictly comparable: the incidence of spontaneous ventricular arrhythmias after surgical repair of tetralogy of Fallot seems to increase with age at the time of operation ${ }^{9-1123}$ and with duration of follow up. ${ }^{9-11} 17$ An increased incidence of ventricular arrhythmias has also been associated with residual right ventricular hypertension, ${ }^{1017}$ reduced right ventricular ejection fraction, the presence of a scar in the right ventricle, ${ }^{10}$ reduced left ventricle function, ${ }^{24}$ or the severity of pulmonary regurgitation. ${ }^{25}$ In patients with uncomplicated repair, the incidence of new ventricular arrhythmias seems to increase only slightly after operation. ${ }^{26}$ Ventricular late potentials are thought to represent delayed activation of small areas of the myocardium. In adults, particularly after myocardial infarction, late potentials indicate a higher risk of ventricular tachycardia or sudden death. ${ }^{27}$ After repair of tetralogy of Fallot, ventriculotomy, infundibular resection, and closure of the ventricular septal defect may provide an anatomical substrate for reentrant ventricular arrhythmias. ${ }^{1328}$ In our study late potentials were less often detected than spontaneous ventricular arrhythmias (23 $v$ 38\%); their incidence seems to increase with age at the time of operation, but no correlation was found between late potentials and the incidence or severity of spontaneous ventricular arrhythmias early after operation. Moreover, the three patients with non-sustained ventricular tachycardia during Holter recording were in the subgroup of patients without late potentials during signal averaging. Our data are different from those of Stelling et al who found a correlation between abnormal signal averaged recordings and inducible ventricular arrhythmias. ${ }^{14}$ Recording methods for late potentials (including filter settings) were not comparable, and in our study only spontaneous clinically relevant ventricular arrhythmias were considered during the follow up; conclusions applied to the result of electrophysiological studies ${ }^{1415}$ may be different, and the prognostic value of programmed ventricular stimulation in postoperative tetralogy of Fallot remains controversial. ${ }^{15} 17$

No normal values for signal averaged recordings are established in the presence of right bundle branch block, neither in adults nor in children; intraventricular conduction defects have important influences on the signal averaged electrocardiogram and criteria to define the presence of late potentials should be modified. ${ }^{1329}$ The normal limits applied in this study were defined according to data obtained in patients with right bundle branch block but no right or left ventricular abnormality; these criteria may not be applicable with other recording equipment.

During the relatively short follow up period, no case of sudden death or sustained 
ventricular tachycardia occurred; therefore, the exact prognostic value of signal averaging and Holter recording cannot be determined from our data. If we consider the frequency of late potentials and spontaneous ventricular arrhythmias, and conversely the rarity of serious arrhythmic events after tetralogy of Fallot on the other side, the positive predictive value of both tests must be very low. A longer follow up and a larger study group would possibly help to better define the true prognostic value of signal averaging and Holter recording after surgical repair of tetralogy of Fallot.

1 Deanfield JE, McKenna WJ, Presbitero P, England D, Graham GR, Hallidie-Smith $K$. Ventricular arrhythmi in unrepaired and repaired tetralogy of Fallot. Br Heart $\mathcal{F}$ in unrepaired and

2 Vetter VL. Sudden death in infants, children and adolescents. Cardiovascular Clinics 1985;15:301-3.

3 Deanfield JE, Ho SY, Anderson RH, McKenna WJ, Allwork SP, Hallidie-Smith KA. Late sudden death after repair of tetralogy of Fallot: a clinicopathologic study. Circulation 1983;67:626-31.

4 James FW, Kaplan S, Chou T. Unexpected cardiac arrest in patients after surgical correction of tetralogy of Fallot. Circulation 1975;52:691-5.

5 Quattlebaum TG, Varghese PJ, Meill CA, Donahoo JS. Sudden death among postoperative patients with tetralogy of Fallot. Circulation 1976;54:289-93.

6 Gillette P, Yeoman MA, Mullins CE, McNamara DG Sudden death after repair of tetralogy of Fallot. Circulation 1977;56:566-71.

7 Fuster V, McGoon DC, Kennedy MA, Ritter DG, Kirklin $\mathrm{JW}$. Long-term evaluation (12 to 22 years) of open heart surgery for tetralogy of Fallot. Am $\mathcal{F}$ Cardiol 1980;46: 635-42.

8 Dunningan A, Pritzker MR, Benditt DG, Benson DW Jr. Life threatening ventricular tachycardias in late survivors of surgically corrected tetralogy of Fallot. Br Heart 1984;52:198-206.

9 Webb Kavey RE, Blackman MS, Sondheimer HM Incidence and severity of chronic ventricular dysrhythmias after repair of tetralogy of Fallot. Am Heart f 1982; 103:342-50.

10 Kobayashi J, Hirose H, Nakano S, Matsuda H, Shirakura R, Kawashima Y. Ambulatory electrocardiographic study of the frequency and cause of ventricular arrhyth-
mia after correction of tetralogy of Fallot. $\mathrm{Am} \mathrm{f}$ Cardiol mia after correction

11 Garson A Jr, Randall DC, Gillette PC, Smith RT, Moak JP, McVey P, McNamara DG. Prevention of sudden death after repair of tetralogy of Fallot: treatment of ventricular arrhythmias. $\mathcal{f} \mathrm{Am}$ Coll Cardiol 1985;6:221-7.

12 Ward DE, Makinen L, Jones S, Carter S, Shinebourne E Signal averaged electrocardiography in infants and children with congenital heart disease. Int $f$ Cardiol 1984;6:669-706.

13 Zimmermann M, Friedli B, Adamec R, Oberhänsli I.
Frequency of ventricular late potentials and fractioned right ventricular electrograms after operative repair of tetralogy of Fallot. Am $\mathcal{f}$ Cardiol 1987;59:448-53.

14 Stelling JA, Danford DA, Kugler JD, Windle JR, Cheatham JP, Gumbiner CH, et al. Late potentials and inducible ventricular tachycardia in surgically repaired congenital heart disease. Circulation 1990;82:1690-6.

15 Zimmermann $M$, Friedli $B$, Adamec $R$, Oberhänsli I. Ventricular late potentials and induced ventricular arrhythmias after surgical repair of tetralogy of Fallot. Am $\mathcal{F}$ Cardiol $1991 ; 67: 873-8$.

16 Vaksmann G, El Kohen M, Schleich JM, Kacet S, Rey C, Dupuis C. Influence de l' âge et de la surface corporelle sur le signal moyenné de l'ECG haute amplification sur le signal moyenne de l'ECG haute amplification après réparation complète des té

17 Chandar JS, Wolff GS, Garson A Jr, Bell TJ, Beder SD, Bink-Boelkens $M$, et al. Ventricular arrhythmias in postoperative tetralogy of Fallot. Am $\mathcal{f}$ Cardiol 1990;65: 655-61.

18 Horstkotte D, Paselk C, Loogen F, Schulte HD, Bircks W, Strauer BE. Fatal ventricular arrhythmias and sudden death are the major cause for mortality late after tetralogy of Fallot repair [abstract]. Eur Heart f 1992; 13(suppl):331.

19 Vaksmann G, Fournier A, Davignon A, Ducharme G, Houyel L, Fouron JC. Frequency and prognosis of Houyel L, Fouron JC. Frequency and prognosis of Fallot. Am 7 Cardiol 1990;66:346-9.

20 Vaksmann G, El Kohen M, Breviere GM, Rey C, Francart $C$, Chammas E, Dupuis C. Incidence et facteurs favorisant les arythmies ventriculaires après réparation de tétralogie de Fallot. Arch Mal Coeur Vaiss 1990;83:659-63.

21 Walsh EP, Rockenmacher S, Keane JF, Hougen TJ, Lock JE, Castaneda AR. Late results in patients with tetralogy of Fallot repaired during infancy. Circulation 1988;77: 1062-7.

22 Deanfield JE, McKenna WJ, Hallidie-Smith KA Detection of late arrhythmia and conduction disturbance after correction of tetralogy of Fallot. Br Heart $\mathcal{f}$ 1980;44:248-53.

23 Fukushige J, Shimomura $K$, Harada $T$, Fukazawa $M$, Tokunaga $\mathrm{K}$. Incidence and severity of ventricular arrhythmia in patients after repair of tetralogy of Fallot. fpn Heart $f$ 1988;29:795-800.

24 Webb Kavey RE, Thomas FD, Byrum GJ, Blackman MS, Sondheimer HM, Bove EL. Ventricular arrhythmias and biventricular dysfunction after repair of tetralogy of Fallot. $\mathcal{F} \mathrm{Am}$ Coll Cardiol 1984;4:126-31.

25 Zahka KG, Horneffer PJ, Rowe SA, Neill CA, Manolio TA, Kidd L, Gardner TJ. Long-term valvular function after total repair of tetralogy of Fallot. Relation to ventricular arrhythmias. Circulation 1988;78(suppl III):14-9.

26 Sullivan ID, Presbitero P, Gooch VM, Aruta E, Deanfield JE. Is ventricular arrhythmia in repaired tetralogy of Fallot an effect of operation or a consequence of the Fallot an effect of operation or a consequence
course of the disease? $\mathrm{Br}$ Heart 7 1987;58:40-4

27 Simson MB. Use of signals in the terminal QRS complex to identify patients with ventricular tachycardia after myocardial infarction. Circulation 1981;64:235-41.

28 Deanfield J, McKenna W, Rowland E. Local abnormalities of right ventricular depolarization after repair of tetralogy of Fallot: a basis for ventricular arrhythmia. $\mathrm{Am}$ 7 Cardiol 1985;55:522-5.

29 Buckingham TA, Thessen CC, Stevens LL, Redd RM, Kennedy HL. Effects of conduction defects on the signal-averaged electrocardiographic determination of late potentials. Am $\mathcal{F}$ Cardiol 1988;61:1265-71. 